\title{
Improvement and Innovation of Application Mode in Foreign Language Teaching \\ Luo Qian
}

Foreign Language College, JingChu University of Technology, Hubei, Jingmen,448000,China

Key words: Applicability; Foreign language teaching; Information extraction; Database

\begin{abstract}
.
In recent years, with the deepening of information technology in the field of education, traditional teaching methods have undergone tremendous changes. In the course of teaching, the relationship between teachers and students and the role of teachers have changed in nature. In this context, the foreign language teaching curriculum design needs to be innovated with the application of information technology, so that it can be combined with the teaching resources to provide targeted and personalized learning environment for different needs of foreign language learners. In this paper, the application of information technology in foreign language teaching has been improved and innovated, and corpus database platform has been established by using information extraction technology. At the same time, foreign language data in the library are qualitatively and quantitatively analyzed. The results show that the improvement and innovation of this application method is beneficial to the students' autonomy in foreign language learning, which can improve the learning efficiency and teaching quality.
\end{abstract}

\section{Introduction}

The main contents of foreign language teaching include two parts, namely, technology and resources. For foreign language teaching curriculum design, we not only should start from theoretical research, but also consider the application innovation of teaching technology, so that the organic combination of it and teaching resources would provide targeted learning environment for different students [1]. At present, with the extensive application of information technology in the field of education, traditional teaching technology has undergone tremendous changes. The improvement and innovation of the application way of information teaching technology in foreign language teaching makes a fundamental change in teacher's role in teaching process and the relation between teachers and students in teaching. As a manager of knowledge transfer, teachers can apply information teaching technology to foreign language teaching, construct knowledge base with intelligent characteristics, pick and classify knowledge points of foreign language teaching, and intelligently integrate relevant knowledge reorganization and aggregation, so that students access to foreign language knowledge more quickly and easily. Through the application of information teaching technology, teaching resources can be networked, and this network teaching resources improve the students' comprehensive ability in learning language, and can make students have higher autonomy in learning process. In teaching process, students make their own choice on the content of knowledge according to their own situation [2].

In this paper, the application of information teaching technology in foreign language teaching is studied. It improves the application of computer technology such as information extraction and retrieval in foreign language teaching, and constructs a new corpus database by re-developing 
various foreign language literature and quantitative analysis of the corpus in the database so that teaching resources can be rich and provide a personalized learning environment for different needs of foreign language learners.

\section{The construction of corpus database}

The so-called corpus database refers to the use of computer information technology in foreign language learning process to present massive foreign language information to students. Corpus database, based on the study of the characteristics of foreign language, summarizes the most authentic foreign language information in the process of foreign language use. This kind of corpus database is not a foreign language knowledge point illustration, but a foreign language knowledge learning resources. This kind of resource-based platform must be based on the qualitative and quantitative analysis of language data. In this paper, English usage information related to each social life is collected, and corresponding Chinese and English retrieval software is applied with words as the key words. XML format file is used as the form for retrieval and retrieve corresponding context sentences, so the full text content can be further retrieved.

English documents in XML format are generated by corresponding document generation software, and then are imported to the search software to form an index. English information is in various forms, including novel prose, essay diary and news reports, involving philosophical history, natural sciences, industrial technology, art music and other aspects, in addition, there are relevant English test question banks. The search of verb "work" can get more than 5000 sentences, which includes the upper and lower context of the verb and the tense of the verb, commonly used collocation and part of speech changes. In example sentence query, full text link is also provided, and the original context with the sentence is shown by clicking on the example sentence.

\section{Application of Extraction Technology in Language Material Analysis}

In the process of analyzing language materials, information extraction technology is mainly for words' part of speech, such as verbs, adjectives, adverbs, nouns and so on. Taking reading comprehension in the questioning part of corpus database as an example, the number of commonly used words is 1503 , which is $79.32 \%$ of the total vocabulary. Among them, the ratio of words below 3 times is $51.23 \%$, more than 3 times and below 10 times is $40.52 \%$. The average value of vocabularies extraction frequency is 4.68 times, and the proportion of verbs is bigger in different parts of speech, which is $84.23 \%$.

For verbs, there are two forms: prototype and tense and voice change. There are 492 prototype vocabularies in the process of extraction, and the average number of occurrences is 4.69 times. There are 284 prototype verbs which occur only once, accounting for more than half of all prototype verbs. And 208 prototypes verbs occur two or more times, accounting for about $42 \%$ of the total. By statistics, these prototype verbs can be divided into the following categories: once occurrences, the actual action is expressed, and the frequency is $32 \%$; the number of occurrences is twice or more, the actual action is expressed, and the frequency is $75 \%$; once occurrences, the emotional thinking of the subject is expressed and the frequency is $12 \%$; the number of occurrences is twice or more, the emotional thinking of the subject is expressed and the frequency is $43 \%$; the number of occurrences is once, the state of the subject is expressed and the frequency is $26 \%$; the number of occurrences is twice or more, the state of the subject is expressed and the frequency is 
$76 \%$; Once occurrences, the expression of the subject is expressed and the frequency is $6 \%$; the number of occurrences is twice or more, the expression of the subject is expressed and the frequency is $45 \%$. The average frequency of verbs expressing subject state, actual action, expression and emotional thinking is $76 \%, 75 \%, 45 \%$ and $43 \%$ respectively. In reading comprehension section in examination question bank, there is a strong relevance. After Chi-square test, the number of occurrences of verbal verbs and the number of occurrences of two or more times expressing the actual action and state of the verb, $X^{2}$ are respectively 15.9, 17.3 and 15.8. The difference between these three types of verbs is more significant when the level is $5 \%$, while the difference between other types of prototype verbs is not obvious. For the transformed verbs with tense and voice transformations, the number of occurrences has the strongest correlation between one and two transitive verbs, respectively. The frequency occurrence is $40 \%$ and $58 \%$ respectively. The verbs are tested by Chi-square, twice occurrences transformed verb $\mathrm{X}^{2}$ is 17.7 .

For adjectives, there are 108 adjectives in the information extraction of examination question bank's comprehension section, and the average number of adjectives is 3.7 times. Once occurrences adjectives are 67 , accounting for about $60 \%$ and the number of occurrences of two or more than is 41, accounting for about $40 \%$. Adjectives are divided into three categories: nature and shape description, human emotions description, the state description of people or things, and their frequency of occurrence are $16 \%, 14 \%$ and $19 \%$. By test variance, the latter two frequencies differ obviously in 5\% level. The adjectives describing human emotions reached the highest frequency of 47\% in 2011, but the frequency was the lowest in 2014, only 8\%, and slightly rose by 15\% in 2015. The nature and shape of the descriptor, the frequency of the adjective that describes the state of person or object, is less different in reading comprehension.

For adverbs, this article has a total of 269. The average occurrence number of adverbs is 2.26 times. The once occurrence adverbs are 60 , and 46 adverbs occur twice or more. The percentages are about $55 \%$ and $44 \%$ respectively. The types of adverbs can be divided into the length of the presentation, the speed of the expression, the frequency of the expression, the degree of expression, and the mimicry and state of the expression. The occurrence frequency of these adverbs is studied. The frequency of adverbs of length expression, degree expression and state expression are high, and the average frequency of occurrence is $48 \%, 28 \%$ and $27 \%$ respectively, and expression speed, expression frequency and mimicry adverbs occurrence frequency are correspondingly lower, 4\%, $5 \%$, and $4.6 \%$, respectively. After variance test, the adverbs expressing length, state and degree have high similarity, which appear in the articles of reading comprehension, and the frequency trend is similar and has obvious correlation.

\section{Results analysis}

By retrieving the corpus resources of words, examples and full text forms and quantitative and qualitative analysis, the following contents are summarized in terms of improving the quality of foreign language teaching and improving learning efficiency.

First of all, for the highest level international English test requirements, the required vocabulary is not all in foreign language teaching materials. Many of the vocabularies that are not commonly used or are not relevant to the profession are not necessary for mastery for professional knowledge for science and engineering foreign language learners whose purpose of studying is professional knowledge, but the uncommon words in the profession need to be grasped. Professional foreign language learning intensity should be strengthened. However, in the process of professional foreign language teaching, we should adhere to gradual thinking, and should not choose too large 
vocabulary in curriculum design, so the language database presented in this article are screened and a total of about 5,000 vocabulary for teaching are selected, in which basic vocabulary is about 3500 and extended vocabulary is about 1500 . This vocabulary can fully meet the purpose of professional foreign language teaching, and for the learners, the grasp of these words is enough for reading and understanding the relevant professional foreign literature purposes. Second, foreign language communication environment is an indispensable part of learners' foreign language learning. However, due to the limited time of foreign language teaching, this language environment can only be created after class. In the process of foreign language teaching, provide "authentic" language environment matching for textual content, and apply it in classroom and after school practice. This is an effective teaching method for foreign language learning. Corpus retrieval provides learners with the sentence context of words and sentences, and even the entire article where the words or sentences appear, accompanied by the standard foreign language reading audio. This context training can stimulate learners' foreign language learning interest while enriching the content of the classroom. It expands the scope and breadth of foreign language teaching, and avoids learners' resistance to mechanical memory and dull knowledge illustration in foreign language learning process. Give full play of learners' subjective initiative so that learners can have a purposeful and independent choice of learning content, which improves the efficiency of foreign language learning and teaching efficiency. Finally, in the process of foreign language teaching, fully consider individual differences. Foreign language teaching objects are different in grasping the same knowledge points in the same teaching environment due to the understanding of language, age, gender and other factors. The development of corpus resources library can guarantee learners' motivation for knowledge. Corpus retrieval can continue to reproduce the teaching content. Learners can make the reproduction and consolidation of knowledge when frustrated. Through mobile client, multimedia resources can be downloaded from the database and the consolidation of knowledge has no time and place restrictions.

\section{Conclusion}

To sum up, current information technology in the field of education will be widely used which will bring far-reaching impact and great changes to teaching technical means and the presenting form of teaching resources. The use of modern information extraction technology to establish a comprehensive rich foreign language database is a reform and innovation of information technology application in foreign language teaching and this innovative means can bring new learning environment for different learners and give full play to learners' foreign language learning autonomy. After all, it is an effective means to improve the quality of foreign language teaching and foreign language learning efficiency.

\section{Acknowledgments}

Fund Project: Teaching research project in Jingchu University of Technology "College English teaching research and practice based on ‘task-driven’ model” (JX-201635) 


\section{References}

[1] Cheng Dongyuan. Foreign language teaching technology [M], Beijing: National Defense Industry Press, 2008. 64-66.

[2] Li Xiuhong. Study on the construction and effect evaluation of second language learning strategy in college students second language autonomous learning [J], Journal of Inner Mongolia Normal University (Education Science Edition), 2011, 1: 128-131. 